\title{
Arte y Medios: Narrativa transmedia y el translector
}

\section{Aguerre, Natalia [ver currículum del autor, docente de la Facultad de Diseño y Comunicación]}

\section{Resumen:}

Los avances en el ecosistema de los medios de comunicación e Internet han transformado las formas de construcción de relatos y los modos de lectura de los sujetos. La narrativa transmedia y el translector son términos que surgieron en las últimas décadas para explicar los actos de producción y lectura en el marco de la actual ecología de medios. Este artículo examinará la evolución de experiencias desde el campo del arte, realizando un recorrido histórico para visualizar cómo determinados artistas han ido modificando sus creaciones narrativas a partir del uso de dispositivos que ofrecen los medios digitales y cómo los receptores fueron asumiendo nuevas prácticas de lectura.

\section{Cuadernos del Centro de Estudios de Diseño y Comunicación N72}

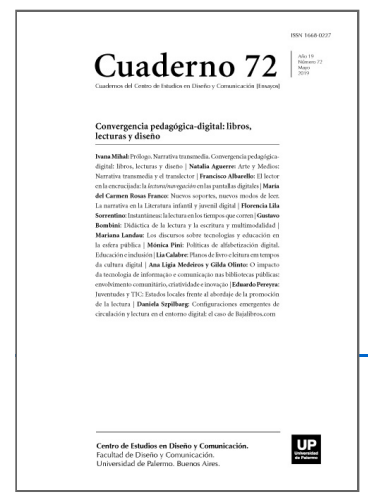

ISSN: 1668-0227

Convergencia

pedagógica-digital:

libros, lecturas y

diseño

Año XIX, Mayo 2019, Buenos Aires, Argentina | 194 páginas

descargar PDF

\section{ver índice de la publicación}

Ver todos los libros de la publicación

compartir en Facebook

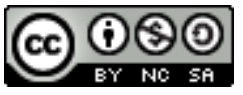

Esta obra está bajo una Licencia Creative Commons Atribución-NoComercialCompartirlgual 4.0 Internacional

Palabras clave: Arte - Medios - Narrativa transmedia - Translector

${ }^{*}$ ) Licenciada en Comunicación Social y Periodismo. Doctora en Comunicación. Profesora de grado y posgrado en la Facultad de Periodismo y Comunicación Social de la Universidad Nacional de La Plata; la Facultad de Diseño y Comunicación de la Universidad de Palermo y de posgrado en la Universidad de Quilmes. Integrante de equipos de investigación -UNLP, CLACSO-, que abordan temas sobre arte y política. Fundraiser y Gestora en Comunicación del Centro de Arte Experimental Vigo.

Introducción

Situarse en y desde la perspectiva de los estudios en comunicación implica desplazarse del examen teórico de los medios y la determinante tecnológica hacia los contextos, mediaciones y las prácticas culturales. Esto implica examinar los fenómenos sociales no desde el lugar instrumental sino relacional (Uranga, 2008), con una mirada 
que enfoque la atención en la construcción, circulación y recepción de sentidos y significaciones, en relación con las dimensiones materiales e históricas.

Hablar de comunicación es reconocer cómo los individuos se apropian de los instrumentos tecnológicos que competen a este campo y de qué manera internalizan la digitalización de la cultura, a partir de una variable sustancial -aunque existen otras- que refiere a la transformación de sus narrativas en bytes. Estas unidades de información son capaces de fluir por diferentes y articuladas plataformas mediáticas -hipermedia- y de ser reproducidas, reeditadas, y redistribuidas fácilmente y a gran velocidad desde diversos marcos.

Según Scolari (2014), la digitalización de los medios ha provocado cambios en la formulación de los contenidos volviéndose una condición necesaria para la vinculación de una trama social hipermediatizada, la cual se ha visto enriquecida por los dominios y funciones que aporta la Internet. Desde las últimas décadas, el campo artístico, particularmente la literatura -en sus singulares géneros- ha experimentado con la Web una modificación sustancial en la creación y exposición de sus prácticas y, de manera más general, de los archivos culturales.

Para muchos autores, Internet es el ámbito que facilita la utilización de múltiples lenguajes, en articulación y combinación con medios y plataformas para la producción de sus narrativas/obras; al tiempo que permite la visibilización de textos o imágenes que dan cuenta del proceso constructivo del artista, de los relatos que cuentan sus trayectorias, vidas privadas, actividades políticas, reseñas críticas, comentarios y una vinculación más cotidiana con sus seguidores.

Este diseño comunicativo compuesto por diversos canales, dispositivos, y aplicaciones y donde las narrativas encuentran en la transmediación una manera de composición y expresión, ha generado que los receptores hayan modificado sus hábitos de lectura y participación. Ellos han pasado de ser un lector/espectador (bajo el modelo de broadcastig) a un internauta como lo señala García Canclini (2007), o un translector en palabras de Scolari (2017). Asumiendo que los medios digitales devienen de procesos históricos transformadores de concepciones y prácticas de los individuos, se considera pertinente examinar cómo estos soportes mediáticos, con sus softwares y estructuras de conexión fueron innovando los relatos y los modos de lectura de los sujetos.

Si se enfoca la observación en el soporte instrumental podríamos salvar la cuestión del problema con facilidad argumentando que las realizaciones estéticas y la participación del lector/espectador se han visto determinadas por los medios y tecnologías de su tiempo. Para dar un ejemplo, basta con mencionar que la producción de imágenes desde las pintadas con carbón y tierra en las cuevas de Altamira hasta las digitales, pasando por la fotografía, el cine y el video, siempre han supuesto una técnica con series de instrumentos y de procedimientos, los cuales provocaron condiciones de eficacia, habilidad y saber.

Sin embargo las técnicas, los artificios, canales y mecanismos digitales que maneja el artista para concebir, construir, y exhibir su trabajo no son solo herramientas inertes que producen significados y sentidos inocentes e indiferentes a su contexto social y político/ cultural. Ellas están atravesadas por recorridos conceptuales, por procesos socio/históricos y formas de participación y lectura que derivan de circunstancias de sociabilidad específicas. Debido a esto, la narrativa transmedia planteada por Jenkins (2003) -y retomada por autores como Pratten (2011); Harvey (2015); o Scolari, (2014, 2017)-, y el término translector acuñado por Scolari (2017), son categorías que posibilitan reflexionar sobre cómo los individuos componen sus narrativas con diferentes 
lenguajes y medios digitales para visualizar el proceso de transformación de las maneras de crear y recepcionar diseños artísticos.

En función de ello, este artículo realizará un recorrido histórico para señalar cómo algunos artistas del campo del happening, la música, literatura y artes plásticas hicieron y hacen uso de los medios digitales variando sus operaciones y cómo los receptores fueron trasladando sus prácticas de lectores, espectadores a internautas, translectores.

Hacia la narrativa transmedia y el translector en el arte digital

A lo largo del tiempo, los sujetos han producido técnicas aplicadas que fueron y son útiles para el desarrollo de los diferentes ámbitos y campos de las comunidades. En virtud de las contingencias, dichos artefactos han colaborado en los cambios de ideas, hábitos y acciones de las sociedades, a la vez que éstos han sido y son transformadores de las variables tecnológicas (Martín Barbero, 2003). Es por eso que las mismas no pueden ser pensadas como meras herramientas, sino como dispositivos atravesados por discursos que disputan poder y lógicas de uso, en contextos que las enmarcan y generan sentidos y que, a partir de ellas y con ellas, se construyen.

El desarrollo de los medios digitales e Internet han reformulado las prácticas de producción, circulación y recepción de contenidos pasando del modelo broadcasting donde los mensajes eran transmitidos de forma unidireccional por una estructura mediática conformada por la prensa, radio, tv, sin vinculación sobre los contenidos; a un ecosistema de medios, en los cuales existen múltiples narrativas exhibidas en diversos canales y plataformas donde los individuos seleccionan e intercambian sus lecturas entre los diversos circuitos tecnológicos.

En esta "red sociotécnica (...) hecha de productores, consumidores, textos, medios e interfaces que mantienen relaciones recíprocas y en las que la llegada de un nuevo medio cambia la estructura de toda la red" (Scolari, 2009, p. 32, en Goncalvez, 2010, p. 16), los sujetos han demostrado la necesidad de modificar sus narrativas apelando a singulares sistemas de significación (verbal, icónico, audiovisual, interactivo); medios y escenarios virtuales (Scolari, 2014, p. 21); y las prácticas de lectura, las cuales requieren de movimientos dentro y a través de los textos y de pasos de un medio a otro (Scolari, 2017).

A consideración de Jenkins (2003), este contexto de conectividad permite reconocer la transmediatización de las narrativas y es por ello que planteó el concepto "transmedia storytelling" para explicar cómo un relato es construido a partir de diferentes lenguajes que se sirven de múltiples medios y programas digitales.

Años más tarde, Scolari (2014), advirtió que si bien estas narrativas están inscriptas en medios digitales se debe considerar al comics como el referente de esta práctica dado que las historias que se desarrollaban en esas tiras fueron apropiadas por el lenguaje televisivo y luego por el cine. Uno de los ejemplos más significativos fue el caso de Superman, una historia que se inició mediante un comics y que pasó por la radio y la televisión -en los años '40- para terminar en la gran pantalla por primera vez, en 1970.

Este relato, asimilado por los medios de comunicación masiva, también se vio intervenido por los lectores/espectadores que no solo se limitaron a consumir el producto cultural sino que ampliaron el mundo 
narrativo mediante sus interpretaciones y comentarios hacia los guionistas -por parte de familiares, amigos o conocidos-, provocando nuevas piezas textuales (Scolari, 2014). En este sentido, Scolari señala que si bien el receptor permite expandir la narrativa, esta propagación no se produce de forma mayoritaria por parte de los receptores, sumado a que los mismos no dejan de ser lectores/espectadores, dado que el medio no les posibilita la realización de una reescritura personal.

En relación al campo del arte, se encuentra a artistas que han utilizado los medios analógicos y digitales e hicieron y hacen uso de la digitalización, planteando nuevas conceptualizaciones que dan cuenta de los cambios en sus maneras de crear. Algunos críticos han denominado como New media art -arte de los nuevos medios-, a las acciones y manifestaciones estéticas producidas mediante instrumentos digitales, especialmente la computadora, ya que "resulta más adecuados para definir este tipo de práctica que aúna al arte, ciencia y tecnología" (Cirelluelo, 2008, p. 9). Arte digital o New media art son términos que remiten a un modo de manejo de la tecnología de comunicación y el dispositivo digital para desplazar y/o transformar las formas de producción, recepción y mediación de los lenguajes estéticos.

Según Mark Tribe y Reena Jana, en su libro "Arte y Nuevas tecnologías" (2006), la categoría de "nuevos medios" (Tribe y Jana, 2006) empezó a utilizarse hacia 1994 cuando las empresas de medios de comunicación tradicionales decidieron expandir su territorio de influencia otorgando un espacio a estos innovadores modos de expresión. Tal es el caso de los CD-ROOMS que, capaces de almacenar información y distribuirla en cantidades inéditas hasta entonces, fueron instrumentos asociados a la idea de nuevos medios que llevaron a las empresas y analistas a preguntarse por el futuro de los diarios en papel, la radio y la televisión.

Estos formatos se trasladaron al ámbito de la estética y la idea de un "arte de los nuevos medios" (Cirelluelo, 2008 , p. 9) también comenzó a difundirse para referirse a un universo de obras relacionadas, de un modo u otro, con estas tecnologías digitales. Este término quedaría asociado a los primeros intentos por encontrar rasgos comunes o puntos de contacto entre la diversidad de experiencias emergentes porque sería falaz no advertir que, desde la invención de la fotografía, el cine, la televisión y distintos medios técnicos de registro y reproducción sonoros, las producciones y prácticas artísticas posteriores se vieron transgredidas por estos medios tecnológicos provocando la reconfiguración del mundo del arte.

Al respecto resulta atrayente mencionar las formulaciones del artista brasileño Eduardo Kac (1996), en referencia a las modificaciones de titulación de una de sus publicaciones. En la introducción a la segunda edición del libro cuyo título es "New Media Poetry: Poetic Innovation and New Techonologies" (1996), señala que la decisión de cambiar el nombre por Media Poetry: An International Anthology se debió al hecho de que diez años después de la primera edición los medios electrónicos y específicamente digitales se habían instalado sustancialmente en las prácticas sociales que obligaban a no elegir por esta denominación. Kac fundamentaba que la identificación habitual de los sujetos con la noción de nuevos medios, principalmente con lo electrónico y digital, dejaba afuera la experimentación con otro tipo de canales comunicativos entre los que menciona medios fotónicos y biológicos. Siguiendo esta línea, Arlindo Machado en "Arte y media: aproximaciones y distinciones" (2000), manifiesta que la articulación y combinación de lenguajes y canales llevaría a que el arte de los medios se constituya con el tiempo en un metalenguaje; es decir, en un espacio de creación y reflexión sobre las nuevas tecnologías capaz de alejarse de los sentidos atribuidos a ellas por la lógica del trabajo y el entretenimiento para reapropiarse de sus dispositivos y reinventarles nuevos usos y contextos. En virtud de ello, el artificio/ficción y la realidad siguen siendo dimensiones separadas donde la realidad es entendida, en palabras de Groys (2016), 
"como realpolitik: la suma de todo lo que se puede hacer, en oposición a una visión irrealista de las condiciones y limitaciones de las acciones humanas" (Groys, 2016 -b-, p. 1). Para el filósofo y crítico de arte, éste era el verdadero significado de la literatura y el arte realista del siglo XIX, ya que los autores presentaban descripciones "sobrias" (Groys, 2016 -b-, p. 1) y elaboradas de las decepciones, frustraciones y fracasos que enfrentaban los héroes románticos, social y emocionalmente "idealistas" (Groys, 2016 -b-, p. 1) cuando intentaban implementar sus ideales en la realidad.

A partir del nacimiento de las vanguardias europeas durante la década del '20, los artistas -entre los más relevantes: Max y Lotte Burchartz, Petr Rohl, Alfred Kemeny, Hans Richter, Tristan Tzara o Hans Arp-, pusieron en tela de juicio al realismo, considerando que las obras de arte no debían mostrar estos deslizamientos sino que tenían que ser reales, tan reales como todos los demás procesos que tienen lugar en el mundo. La obra de arte se entendía como algo entre otras cosas, como un teléfono o una bicicleta. Esto no significaba que los artistas de vanguardia no quisieran cambiar la percepción de los sujetos; por el contrario, radicalizaron este deseo. De hecho, esta vanguardia trató de convertir a sus lectores/espectadores en habitantes de la obra de arte, de modo que al acomodarse a las nuevas condiciones de su entorno, los públicos cambiarían sus sensibilidades, actitudes (Rancière, 2004), y las formas de participación y lectura.

Estas concepciones fueron naturalizadas por los artistas argentinos de vanguardia de los años '60 encontrando su materialización mediante el uso de los medios masivos y las computadoras. Tal es así que se puede enunciar el primer antecedente de una computadora puesta al servicio de una expresión estética con la obra "Circuitsuper heterodyne" (Ver Figuras 1 y 2), presentada por Marta Minujin, en "Expo Montreal" durante 1967 (Alonso, 2005).

Para la elaboración de la experiencia "Circuit - Super Heterodyne", Minujin publicó en el diario una encuesta para que aquellos interesados en asistir la completaran y la remitieran a la organización del evento. Luego de obtenerlas realizó una selección de los participantes a través de una computadora que escogía a personas con características afines. En el momento del happening, las imágenes que se proyectaban frente al público, referían a datos personales de los mismos que, de forma simultáneamente y mediante circuitos cerrados de televisión, provocaban la observación de las pantallas por parte del público presente y la atención entre ellos.

La artista se sirvió de variadas narrativas para la producción de su happening como el dispositivo de la encuesta mediada por la prensa gráfica, las imágenes con soporte audiovisual transmitidas en sistemas cerrados de televisión, y la computadora como instrumento de elección. La organización de los relatos gráficos, visuales y sonoros en diferentes medios le permitió plantear una participación interactiva entre la máquina y su receptor y entre éste y los demás asistentes. El happening facilitó la alteración de los asistentes pasando de ser espectadores de una representación pública, y quienes contemplan la obra según la distancia con los actores u objetos, a sujetos que debe incluir sus capacidades de lectura, escritura (del diario y encuesta), y que forman parte de la actuación por ser observados por otros a quienes también observa.

Dos años más tarde, el Instituto Di Tella exhibió la muestra "Arte y Cibernética" donde expusieron artistas norteamericanos, ingleses y japoneses. Ese mismo año el CAYC (Centro de Arte y Comunicación) invitó a Buenos Aires a los integrantes del grupo japonés Computer Technique Group para dar un taller sobre dibujo asistido por computadoras a un grupo de artistas locales, donde luego plantearon una exposición que se denominó "Argentina Inter-medios”. En su catálogo el director del CAYC, Jorge Glusberg expresaba: 
En Argentina Inter-medios el uso de la música electrónica, filmes experimentales, poesía, proyecciones, danza, esculturas neumáticas y cinéticas, constituye un environment total donde los diferentes estímulos, en un intercambio diná- mico, ponen los medios al servicio de la percepción audiovisual. Con espectáculos de este tipo, se intenta llamar la atención de especialistas y científicos en disciplinas sociales y del público avisado, para plantear una integración interdisciplinaria que mejore y amplíe el escenario de las inquietudes humanas. (Alonso, 2005, p. 2)

Pero el hito "del medio al servicio de la percepción audiovisual" (Glusberg, 1969, en Alonso, 2005, p .2), y en los modos de lecturas de pantallas (Murolo, 2012) se produjo con la difusión de la televisión por cable (1980), ya que promovió que el aumento de la oferta de canales condujera a una movilidad de capturas de contenidos y a una fragmentación de las audiencias. Aunque en sus inicios este servicio no era masivo, con el transcurrir de los años alcanzó una mayor difusión produciendo en la comunidad de televidentes el paso de la paleotelevisión donde no había diversidad de canales-, al zapping de la neotelevisión en el que el televidente podía y puede elegir entre decenas de opciones, a decir de Umberto Eco (1983). Estos nuevos hábitos fueron acompañados por la expansión de las computadoras personales, las cuales proponían con sus diseños la adopción de inéditos modos de escritura y tratamiento de los dispositivos audiovisuales. Esta tecnología de comunicación promovió en los artistas la indagación de sus códigos y softwares para la construcción y realización de propuestas discursivas alternativas. A partir de ello, la hipermedia fue un programa que viabilizó y fomentó la apertura de originales maneras de creación con una recepción interactiva (Scolari, 2003).

La hipermedia consiste en un diseño digital cuyos textos se encuentran codificados en diferentes lenguajes textos, sonido, imagen, programas-, lo que significa que pueden leerse/escucharse/verse siguiendo recorridos alternativos de lectura. Al igual que en el hipertexto1, no existe en el hipermedia una lectura única preestablecida sino un conjunto de posibles recorridos sobres los cuales el lector construye su propio camino. En este sentido, Roland Barthes manifiesta que:

En este texto ideal, abundan las redes (reseaux) que actúan entre sí sin que ninguna pueda imponerse a las demás; este texto es una galaxia de significantes y no una estructura de significados; no tiene principio, pero sí diversas vías de acceso, sin que ninguna de ellas pueda calificarse de principal; los códigos que moviliza se extienden hasta donde alcance la vista, son indeterminables...; los sistemas de significados pueden imponerse a este texto absolutamente plural, pero su número nunca está limitado, ya que está basado en la infinidad del lenguaje. (Barthes, 2009, p. 43)

Se puede decir entonces que todo hipermedia es interactivo en tanto que facilita y requiere -en la mayoría de los casos-, la intervención del receptor. De esta manera, el lector/espectador adquiere una intervención activa frente a la narrativa ya que es él quien lo resignifica y escoge el orden de las mismas en la navegación del hipermedia; y quien, en ocasiones, puede modificar esos contenidos respondiendo a las peticiones del creador. Ésta, por su parte, obedece las directrices del receptor estableciéndose así una relación mediada por la máquina entre el sujeto/participante y el dispositivo.

Durante los años '80, el uso del hipermedia por escritores dio lugar a un género denominado "Hiperficción" o "Ciberliteratura" (Rico 2012). Esta forma literaria siguió los pasos de aquellas obras que en la segunda mitad del siglo XX cuestionaron tanto la linealidad del discurso como el rol intocable del autor. En nuestro país, "Kolon" de Raúl Lilloy (1996)2, puede considerarse como uno de los primeros hipermedios narrativos y la primera novela 
en Internet. En este sentido, la novela -que trata a través de la trama de una épica fantástica que transforma la conquista de América al año 3492- se concreta en internet, ofreciendo su página principal 11 accesos que conducen a fragmentos de texto e imágenes míticas en relación con el hecho histórico.

Se puede asociar esta propuesta con el término de neotelevisión de Eco (1983) -que se ha mencionado en párrafos anteriores-, dado que de la misma manera que el televidente decide qué mirar entre las variadas opciones que proponen los canales, el lector de ciberliteratura está habilitado para seleccionar, interrumpir e ir y venir en la lectura de la obra. La distinción de esta experiencia se encuentra en la capacidad de hacerlo en un tiempo que no está programado y estipulado por las emisoras. De este modo, el lector posee una libertad de elección de la práctica que retoma al libro impreso, pero que los medios de comunicación masiva nunca concibieron.

Simultáneamente, el campo de la música encontró en la electroacústica las posibilidades técnicas necesarias para materializar sus inquietudes expresivas. Las innovadoras búsquedas estéticas en convergencia con lo tecnológico/científico llevaron a los compositores a adoptar el dígito como parámetro de exploración del fenómeno sonoro para, través de él, producir una mayor sensibilidad hacia todas las dimensiones del sonido para así indagar en los nuevos tipos de expresividad.

Además de estudios informales de matemática, física y electrónica, los compositores se interesaron por la psicología (especialmente la Gestalt) para estudiar con mayor profundidad las sensaciones que el sonido produce en la conciencia humana. En este marco, la cuestión técnica se volvió capital. Fue el eje sobre el que se articuló el cambio estético que implicó, entre otras cosas, el rechazo del concepto de artista inspirado y producto del siglo XIX en pos de una visión más moderna según la cual el autor se involucra con los instrumentos y materiales que otorgan la producción, pero desde una actitud intelectual. En la Argentina, la música electrónica fue reconocida y valorada por la academia por su capacidad de representar su propio tiempo. El ingeniero platense von Reichenbach logró captar y materializar lo que músicos, artistas visuales y el equipo del C.E.A (Centro de Experimentación Audiovisual del Instituto Di Tella) imaginaban para sus espectáculos y obras participativas. Es así que creo el convertidor gráfico analógico al que apodó "Catalina", el cual permitía traducir imágenes a sonido. También desarrolló un sistema automático de interconexión de equipos, un programador de parlantes, aparatos lectores de microfilms para sondajes ionosféricas, un teclado de luces para el C.E.A., una perforadora ultrasónica y varios equipos de electrónica industrial y electromedicina.

Estas renovadoras tecnologías de la escucha cementaron nuevas competencias y experiencias en el modo de recibir el fenómeno. Una vez que los compositores advirtieron que la tecnología les facilitaba ampliar el campo perceptivo y material del lenguaje musical fueron muy pocos los que rechazaron este progresivo desarrollo que logró revitalizar la ilusión de los artistas y al público de la música electrónica.

Por el lado del arte plástico, Gyula Kosice y Ladislao Gyom conformaron el grupo TEVAT (Tiempo, Espacio, Vida, Arte y Tecnología), a través del cual iniciaron un programa de investigación (1994) para dar cuenta que el diseño del ciberespacio, la realidad virtual, y la inteligencia artificial anunciaban un futuro de posibilidades inéditas que serían insondables para el arte. Las narrativas estéticas más ligadas a las instalaciones y a la participación de los sujetos de forma presencial fueron incorporándose al arte digital, a partir del impulso dado por algunas instituciones que durante los años 2000 promovieron actividades como concursos y talleres de aprendizaje en este campo entre los que cabe mencionar al Centro Cultural España en Buenos Aires y Córdoba, 
a través del Media LAB, y en el Espacio Fundación Telefónica. En los últimos años también surgieron festivales como FACE organizado anualmente por la artista y curadora Graciela Taquini y el Festival 404 en Rosario con "Maestría de Artes Tecnológicas".

Desde hace décadas, Jorge Crowe lleva adelante un proyecto de investigación y producción de obras compuestas por desechos electrónicos, máquinas en desuso como parlantes, grabadores, monitores de P.C., cables y juguetes viejos. (Ver Figura 3)

Con ellos y mediante alternativas conexiones e instrumentos, Crowe produce dispositivos dedicados a la elaboración de sonidos e imágenes en el marco de una propuesta conceptual de distorsión y desorden. Las tecnologías desechadas son rescatadas para ser devueltas a la cotidianeidad de la vida de los sujetos, en forma de aparatos imprevisibles. Esta proposición encuentra sus bases en la vanguardia europea de los años '50 con las máquinas célibes de Michel Carrouges y las máquinas irónicas de Jean Tinguely; y en nuestro país con las máquinas inútiles de Edgardo Antonio Vigo. (Ver Figura 4)

Tanto Crowe como Carrouges, Tinguely o Vigo son creadores que componen con las tecnologías de su tiempo, narrativas artísticas y modos alternativos de expresión poniendo en crisis el lenguaje y la institución artística. En virtud de ello, sus producciones y acciones adquieren un carácter político en tanto que "suspenden las coordenadas normales de la experiencia sensorial" (Rancière, 2011, p. 35), construyendo un arte relacional/participativo que reclama un desplazamiento de la percepción y una reconfiguración de los lugares de presentación.

En cualquiera de los campos y acciones descriptas, el rol del lector/espectador comenzó a vislumbrar cambios en las formas de percibir y vincularse con las obras mediante la manipulación de los objetos, las modificaciones en la apreciación de la escucha y la visión, y las maneras de recepcionar las creaciones en los medios digitales. A partir de ello, los receptores asumieron una lectura multimodal que fue provocando una traslación del sujeto lector y/o espectador -donde el hábito establecía una lectura individual de un único texto y donde el asistente a un espectáculo público solo observaba alejado de la escena representacional-, a un internauta que "lee, ve, escucha y combina materiales diversos, procedentes de la lectura y de los espectáculos" (García Canclini, 2007, p. 32).

Con la difusión de la Web a fines de los '90, los artistas que accedían a este espacio/tiempo virtual se vieron nuevamente interpelados en la exploración de sus programas y propiedades interactivas para hacer uso de los mismos. Desde 1996, el denominado Net.art fue uno de los primeros y más difundidos géneros del arte digital teniendo entre sus primeros cultores al grupo formado por Gustavo Romero, Jorge Haro, Belen Gache y Carlos Trilnick reunidos en torno al espacio virtual "Fin del Mundo" -multimedia, net.art, tecnopoesía, videoarte-.

El Net.art plantea una diseño comunicacional interactivo cuyo soporte instrumental son computadoras conectadas a Internet. Su particularidad radica en la necesidad de conectividad para producir narrativas transmedia utilizando múltiples medios y plataformas para el intercambio simbólico, los cuales pueden realizarse entre las obras y sus receptores, entre los mismos receptores mediante las obras o entre los artistas y receptores en tiempo real. Con mayoría de artistas de Europa del Este, el Net.art surgió como una aproximación a las visiones que, en las primeras etapas de Internet, eran un tanto utópicas por el limitado acceso a la Web. 
En los últimos años, por ejemplo Ciro Múseres ha abordado una crítica tanto tecnológica como estética sobre las potencialidades de la red. Su obra se destaca precisamente porque trabaja sobre las posibilidades de concebir una acción política desde y sobre las redes sociales online En este sentido, Múseres encarna las indagaciones sobre Internet como medio, sobre la participación del usuario y la concepción de la red como plataforma de creación de prácticas artísticas, haciendo uso de la red como soporte de sus creaciones apelando a la narrativa transmedia para la realización de sus producciones3.

Es así que en sus obras se puede observar la combinación de lenguajes textuales y audiovisuales, en combinación con los dispositivos que ofrece Internet; al tiempo que encontramos en otros medios fragmentos o exposiciones presenciales de esas mismas piezas, críticas de especialistas, su bibliografía personal y de experiencias estéticas anteriores, además de comentarios de sus seguidores.

El diseño de la Web brinda a los artistas una serie de respuestas establecidas que no se alteran frente a las "entradas"/acciones de los usuarios, produciendo con ello un mismo resultado. Esto se puede visualizar en el caso de Múseres donde las obras adquieren una lectura de interpretación. Pero existen programaciones esencialmente interactivas, en las que los usuarios intervienen introduciendo datos donde la organización establecida permite su procesamiento y modificación. Ejemplo de ello son los weblogs, los foros, los juegos como Second Life, los Sims, o Creatures, entre otros.

Estos planteamientos posibilitan una lectura mínima, con opciones reducidas a la secuencia lineal de la navegación; exploratoria mediante las búsquedas de opciones; condicionales, con iniciativas que se activan o desactivan en función de las acciones propuestas; contributoria, donde los usuarios incluyen elementos al programa (Fainholc, 2001).

En este sentido, Scolari (2017) plantea que la red sociotécnica genera en los sujetos receptores:

Un dominio de diferentes lenguajes y sistemas semióticos, desde el escrito hacia el interactivo, pasando por el audiovisual en todas sus formas (...) el translector debe moverse en una red textual compleja formada por piezas textuales de todo tipo y ser capaz de procesar una narrativa que, como una serpiente, zigzaguea entre diferentes medios y plataformas de comunicación. (Scolari, 2017, p. 45)

A diferencia de las lecturas mínimas, exploratorias y contributarias (Fainholc, 2001) que bien podrían tipificar la práctica de lectura del internauta, en términos de García Canclini (2007), el translector no solo se limita a indagar e interpretar las narrativas exhibidas sino que debe transmediar los relatos para apropiarse de ellos y adquirir un conocimiento acabado de los mismos (Scolari, 2017). En este sentido entendemos a la obra de Múseres como una narrativa transmedia que genera una conducta translectora. Pero Scolari (2017) advierte que a estas prácticas multimodales se le deben agregar las competencias (pos) productivas de los lectores. Estas capacidades permiten la co-creación, a partir de las relaciones mediatizadas por la Web entre autores, fans y receptores casuales produciendo que las obras dejen de ser patrimonio exclusivo del autor.

Dado que en el campo del arte, las narrativas transmedia son vastas y algunos creadores no conocidos en el ambiente por no poseer una trayectorias en el medio, y en función de que el territorio de los usuarios es difícil de mapear porque los relatos no poseen autorías concretas, ni fronteras en sus contenidos y en sus 
temporalidades; se han decido limitar la definición de translector para la elaboración de este artículo como un lector transmedia. Sin embargo, creemos pertinente hacer una explicación más amplia de este concepto.

Reconociendo que la narrativa transmedia se caracteriza por el entrecruzamiento entre los productores de relatos, la industria de los medios y la lectura/intervención de los usuarios; advertimos que la mayor parte de las narrativas transmedia más populares se desarrollan con contenidos que han surgido de novelas o films, que han pasado por los medios de comunicación de masas, para luego trasladarse a los formatos digitales. Tales son los casos de "Star Wars", “Juego de tronos" o" Harry Potter". Una historia que surgió en una película como el caso de Star Wars, continuó en un cómic, libro, en una serie, videojuegos, revistas y vestimenta. Un relato que se originó a través de la publicación de un libro como Harry Potter se extendió al cine y ahora en la en la web Fanfiction.net donde los fans comparten sus gustos y apreciaciones de sus personajes preferidos.

Estos relatos transmedia estimulan a cierto tipo de receptores a una táctica de lectura casi detectivesca; es decir, donde se debe "reunir todas las piezas del puzzle, saber dónde termina la obra, si es que la obra termina" (Mora, 2012, p. 15). Como también generan otras instancias para expandir el campo narrativo con diversos componentes textuales o audiovisuales. En cualquier caso, los lectores están sumidos en la industria de los medios digitales, las cuales proveen plataformas y aplicaciones más aptas que otras, pero sustancialmente efectivas para el desarrollo de este tipo de prácticas.

Bajo esta premisa, se podría preguntar si Internet es tan democrática y muestra todo lo existente cuando se utiliza. Para ello se puede plantear un ejemplo a través de los dominios de la empresa Google. Esta compañía preselecciona y prioriza cierto tipo de documentación construyendo un ordenamiento retrospectivo de información y generando en el usuario la atención a las primeras páginas que aparecen en nuestros monitores. Es así que el usuario solo puede ver lo que Google exhibe produciendo con ello una incipiente disputa por el acceso universal al libre flujo de la información (Van Dijck, 2016). En este marco, se pueden encontrar nuevas generaciones que perciben las tecnologías de comunicación e Internet como "algo dado" y por ello como una infraestructura que no se cuestiona. Resulta entonces fundamental la explicación y análisis de las estructuras ideológicas que conforman estos microsistemas para aportar una historia y educación crítica de estos medios conectivos.

Retomando la línea argumental, se señala que con la Internet y el aumento de los dispositivos móviles, el translector de las narrativas transmedia artísticas ha provocado un desplazamiento de las instituciones tradicionales -museos, galerías, prensa gráfica-, hacia la Red constituyéndose como la plataforma principal para la exhibición y publicación de obras y archivos documentales y museográficos, como también de la participación y lectura de este tipo de relatos expuestos. Como se ha dicho, las piezas de un autor particular (contemporáneo o de otras épocas) se pueden encontrar en Internet en el contexto de otro tipo de narraciones sobre el creador que se encuentra allí: antecedentes artísticos, actividades políticas, críticas, datos personales, etc. No solo eso, los artistas producen y dan a conocer sus obras de la misma forma que compran entradas, hacen reservas en restaurantes, realizan transacciones bancarias negocios.

Todas estas actividades tienen lugar en el mismo espacio integrado, y todas ellas son potencialmente accesibles por y para otros usuarios. Aquí la obra se vuelve real porque está constituida con datos e información sobre su autor como una persona física. De esta manera, la experiencia artística contempla la totalidad de los actos del sujeto/autor pero trasladando el rito presencial hacia al espacio/tiempo virtual. En consecuencia lo que se 
presenta es un tipo específico de actividad documental que registra un proceso de trabajo que tiene lugar en el mundo real, fuera del soporte artificial aunque también lo incluye. Pero ¿se puede llamar arte a las expresiones publicadas en Internet? ¿Qué aspectos lo legitiman? ¿Qué rol ocupa el usuario en esta legitimación si es que existe?

En este sentido, es viable compartir los postulados de Groys (2016 -a-) al considerar que las obras expuestas en Internet más que operaciones de creatividad específicas son un tipo de documentación artística porque estas producciones refieren a un proceso de trabajo que incluye un evento de arte, instalación o proyectos que pretende dar cuenta de una opinión crítica sobre el medio -como el caso de Múseres-. "En el mundo contemporáneo nos enfrentamos de hecho no con el arte sino con información sobre el arte" (Groys, 2016 -a-, p. 196). Asimismo, cabe observar lo que ocurre en los medios de arte y con sus prácticas de la misma manera que lo que está sucediendo en otras esferas de la vida social: mediante el uso de redes sociales contemporáneas como Facebook, YouTube e Instagram.

En cualquier caso, la documentación artística compendiada y publicada en Internet encuentra su lugar legítimo porque posibilita transparentar y visibilizar el proceso creativo en su "real" -referente externo- articulándolo con las formas de producción de los diseños web y las variables de acceso y participación de los usuarios. Se puede decir que el arte de vanguardia de los años '50, '60 ha logrado finalmente su objetivo porque la obra forma parte -como otros objetos- de la realidad cotidiana de los sujetos, en tanto convive con otros productos que hacen al quehacer cotidiano.

Internet es el espacio/tiempo en el que los sujetos se exhiben y son observables. La documentación artística es tan vasta y los públicos tan fragmentados y diversos que los autores han trasladado sus recorridos de lo global a lo local. Antes, la reputación de un autor -escritor o artista- se conformaba por sus inscripciones en lo local para luego establecerse en el ámbito internacional. En la actualidad "colgar" una obra significa compartirla de modo directo con la audiencia global generando una nueva noción de realismo en el arte -como se ha mencionado-y una definición del éxito desde la dimensión cuantitativa, dado por el nivel de interacción/lectura -o clic/visita- de los usuarios.

En palabras de Castells (2010), la Web posibilita la auto/comunicación de masas, ya que ofrece a los usuarios un escenario donde forjar una imagen de sí y luego popularizarla fuera de sus círculos más íntimos. Pero esta identidad no visualiza las reacciones en la percepción de las narrativas transmedia del arte digital. Para ello sería destacado elaborar un estudio que indague en los modos de apreciación y resignificación de los translectores, en el marco de la cibercultura. A este análisis cabe agregar la perspectiva que combina los estudios culturales con la economía política. David Marshall (2002) propone el concepto de mercancía intertextual para advertir cuáles son las estrategias de comunicación (Massoni y Pérez, 2009) de las industrias de medios para captar nuevos usuarios. Las estrategias de promoción de los productos mediáticos se han ido haciendo cada vez más complejas, “incluyendo el placer de la anticipación, el suministro de información de background y otras maniobras que profundizan la inversión afectiva y cognitiva de la audiencia en el producto cultural" (Marshall, 2002, en Scolari, 2014, p. 23).

La creciente utilización de dispositivos móviles y de nuevas aplicaciones y plataformas digitales podría fundamentar lo propuesto por Marshall (2002). Y junto con estas incorporaciones encontramos que los sujetos producen o reeditan textos, y leen en formatos más breves o efímeros. Lo mismo acontece en los diseños 
audiovisuales donde existen los clips, tráileres, cápsulas informativas, o mobisodios. Los cambios en el ecosistema de medios obligan a volver sobre algunos conceptos como "lector", "espectador", "audiencia", "sociedad de masas", los cuales responden a las teorías del broadcasting, pero que en la actualidad no dan cuenta de las modificaciones en las prácticas culturales.

Avanzar en la comprensión de la complejidad que caracteriza a la nueva ecología mediática implica desplazarse teóricamente del examen de los medios masivos y la determinante tecnológica hacia la transmediatización de las prácticas culturales. Esto conlleva examinar los fenómenos sociales no desde el lugar instrumental sino relacional (Uranga, 2008), con una mirada semiótica que enfoque la atención en el plano simbólico, en vinculación con las dimensiones materiales e históricas.

Así los debates sobre las producciones artísticas en los medios digitales y las lecturas deberían contemplar la presencia de nuevos actores empresariales tecnológicos, económicos, políticos y culturales para examinar estas experiencias "inacabadas, con un sinnúmero de tareas por cumplir" (Freire, 2007, p. 47). Entre ellas, se pueden mencionar las acciones y políticas de reducción de las brechas digitales para propiciar un igualitario acceso y uso de los medios digitales.

\section{Conclusión}

Las tecnologías y los medios de comunicación han transformado las formas de concepción y presentación de las obras y los modos de acceder y participar, en tanto que las mismas son productoras de sentidos sociales. En función de ello, podemos pensar en un tipo de retroalimentación o doble articulación (Martín Barbero, 2003), ya que los individuos producen a las tecnologías y estas modifican a los sujetos en sus representaciones y prácticas sociales, en sus modos de ser, estar y pensar el mundo.

La conectividad y digitalización ha favorecido el abaratamiento de costos de producción y de difusión facilitando una apertura de estas prácticas a artistas y/o grupos alternativos que antes se veían imposibilitados de compartir con otros autores sus acciones. Esta pluralidad también se vio fortalecida en la relación autor-receptor ya que en virtud de los diseños de los soportes o de interfaces, tanto los artistas como los usuarios forman parte del acto creativo. Con ello se deja de lado la concepción individual de las producciones estéticas para concebir la expresión de forma colectiva donde el usuario también es partícipe de la acción.

La Web se convirtió en un instrumento que ha superado las barreras del espacio/tiempo facilitando una conexión permanente y desde cualquier sitio para la producción, publicación y recepción de las expresiones artísticas. Este diseño comunicativo compuesto por diversos canales, dispositivos y aplicaciones donde las narrativas se transmedian, han provocado que los receptores hayan cambiado sus modos de lectura y participación pasando de ser un lector/espectador a un internauta como lo señala García Canclini (2007) para convertirse en un translector, en palabras de Scolari (2017).

En función de ello, este artículo tuvo como objetivo la observación de las acciones de determinados artistas para visualizar cómo, a través del tiempo, fueron transformando sus narrativas, a partir del uso de instrumentos que ofrecen los medios digitales y cómo los receptores fueron asumiendo nuevas prácticas de lectura. 
Estos nuevos códigos de los medios digitales y la Internet adquieren formas narrativas que se transmedian para una mayor optimización de las operaciones y circulación de las obras. Por el lado de los receptores, éstos han pasado del rol de lectores/espectadores que solo presencian las experiencias mediante una lectura individual de un único texto o por su asistencia a un espectáculo público, a sujetos que mantienen una lectura multimodal donde los estímulos sensitivos de la visión y la escucha se combinan con diversos lenguajes y soportes generando un translector que busca, lee, escucha, conoce y se entretiene mediante una tejido intertextual que se articula entre diferentes medios y plataformas digitales de comunicación.

Estos nuevos escenarios y tramas sociales nos desafían a seguir discutiendo y reflexionando y es nuestro compromiso como intelectuales de las ciencias sociales ensayar posibles respuestas a estos interrogantes para iniciar el debate y plantear nuevas preguntas.

Notas

1. Sistema de almacenamiento de textos. Una escritura no lineal, textos que se bifurcan y permiten al lector tomar decisiones, para ser leídos en una pantalla interactiva. Con el hipertexto podemos crear nuevas formas de escritura que reflejen la estructura de aquello sobre lo que escribimos y los lectores pueden elegir diferentes caminos de acuerdo a su interés y el flujo de sus pensamientos.

2. Dicha novela puede encontrarse disponible en el sitio http://www.elaleph.com/libro/ Kolon-3492-de-RaulLilloy/992103/

3. Algunas de sus obras se pueden consultar en los siguientes sitios: Yah0000000000000 00000000! (2005); http://www.hyoooooo.museres-ciro.com.ar/; “Untitledocument” (2005); http://untitledocument.museresciro.com.ar/; “No-pro" (2007). En: http://untitledoc.com/no-pro/

Bibliografía

Alonso, R. (2005). Arte y tecnologías en Argentina: los primeros años. Disponible en: http:// www.roalonso.net/es/arte_y_tec/primeros_anios.php

Barthes, R. (2009). S/Z. Buenos Aires: Ed. Siglo Veintiuno.

Castells, M. (2010). Comunicación y poder. Madrid: Ed. Alianza.

Chistofides, E; Muise, A. y Desmarais, S (2009). Ciberpsychology and Behaivor. Disponible en: online.liebertpub.com

Cirelluego, L. (2006). Lo digital en el arte. Madrid: Ed. Museo Nacional Centro de Arte Reina Sofía.

Eco, U. (1983). La TV. La transparencia perdida. Disponible en: "omegalfa.es/downloadfile. php?file=libros/t-v-latransparencia-perdida.pdf

Fainholc, B. (2001). La práctica de lectura crítica en Internet. Disponible en: http:// es.slideshare.net/abc/lecturaen-internet 
García Canclini, N. (2007). Lectores, espectadores e internautas. Barcelona: Ed. Gedisa.

Groys, B. (2016 -a-). Arte en flujo. Ensayos sobre la evanescencia del presente. Buenos Aires: Ed. Caja Negra.

Groys, B. (2016 -b-). "Towards the new realism”. Disponible en: http://www.e-flux.com/ journal/77/77109/towardsthe-new-realism/

Kac, E. (1996). Media Poetry: An International Anthology. Bristol: Ed. Intellect.

Machado, A. (2000). El paisaje mediático. Buenos Aires: Ed. Del Rojas UBA.

Marshall, D. (2002). The new intertextual commodity. Londres: Ed. Harries, Dan British Film Institute.

Martín Barbero, J. (2003). De los medios a las mediaciones. Buenos Aires: Ed. Gustavo Gili. S.A.

Massoni, S. y Pérez, R. (2009). Hacia una teoría general de la estrategia. Buenos Aires: Ed. Ariel Comunicación.

Mora, V. (2012). El lectoespectador. Barcelona: Ed. Seix Barral.

Murolo, L. (2012). "Nuevas pantallas: un desarrollo conceptual”. En Razón y Palabra, N 80. Disponible en http://www.razonypalabra.org.mx/N/N80/V80/24_Murolo_V80.pdf

Rancière, J. (2004). El malestar de la estética. Buenos Aires: Ed. Capital Intelectual.

Rico, F. (2012). "La narración literaria analógica y la narración literaria digital. Análisis interdiscursivo de II castello dei destini incrociati, de Italo Calvino, y Gabriella Infinita, de Jaime A. Rodríguez Ruiz". En Ferrer, F. y Rico, F. (eds). Ciberliteratura y comparativismo, pp. 63-74. Universidad de Alicante. Disponible en http://cmap.javeriana.edu.co/servlet/ SBReadResourceServlet?rid=1KFJ3V8ZG-VBVVG9-33F

Scolari, C. (2017). "El Translector. Lectura y Narrativas Transmedia en la nueva ecología de la comunicación". En Millán, J. (coord.) La lectura en España. Informe 2017, pp. 175-186. Disponible en: http://www.fge.es/lalectura/docs/Carlos_A_Scolari\%20_175-186.pdf

Scolari, C. (2014). Las narrativas transmedia. Cuando todos los medios cuentan. Buenos Aires: Ed. Grupo Planeta.

Tribe, M. y Jana, R. (2006). Arte y Nuevas tecnologías. Buenos Aires: Ed. Taschen.

Uranga, W. (2008). "Prospectiva estratégica desde la comunicación”. Disponible en: https:// catedrabdcv.wikispaces.com/file/view/uranga.pdf

Van Dijck, J. (2016). La cultura de la conectividad. Buenos Aires: Ed. Siglo XXI.

Vigo, E. A. y Zabala, H. (1976). "Arte Correo". Revista Hexágono '71. Centro Experimental de Arte Vigo. Disponible en: http://caevediciones.blogspot.com.ar/p/hexagono-71.html / 
Abstract: Advances in the ecosystem of the media and the Internet have transformed the ways of building stories and the modes of reading of subjects. The transmedia narrative and the translector are terms that emerged in the last decades to explain the acts of production and reading, within the framework of the current media ecology. In order to observe these changes, the article will examine the evolution of these experiences from the perspective of the field of art. There will be a historical overview to visualize how certain artists have been modifying their narrative creations, based on the use of devices offered by digital media and how the receivers have been assuming new reading practices.

Key words: Art - Media - Transmedia Narrative - Translector.

Resumo: Os avanços no ecossistema da mídia e da Internet transformaram as formas de narração e os modos de leitura dos assuntos. A narrativa transmedia e o translector são termos que emergiram nas últimas décadas para explicar os atos de produção e leitura, no âmbito da atual ecologia da mídia. Para observar essas mudanças, o artigo examinará a evolução dessas experiências no campo do art. Haverá um passeio histórico para ver como certos artistas do acontecimento, música, literatura e artes plásticas têm modificado suas criações narrativas, do uso de dispositivos que oferecem mídia digital e como os receptores estavam assumindo novas práticas de leitura.

Palavras chave: arte - mídia - narrativa transmedia - translector.

[Las traducciones de los abstracts al inglés y portugués fueron supervisadas por el autor de cada artículo]

Arte y Medios: Narrativa transmedia y el translector fue publicado de la página 17 a página32 en Cuadernos del Centro de Estudios de Diseño y Comunicación Nº72 